\title{
Enhancing First Year Management Students' Engagement: An Action Research Project to Explore the Use of the Essay Feedback Checklist (EFC)
}

\section{Abstract}

Feedback represents one of the key factors that affect student learning. A question is raised here as to what extent engaging students with feedback and considering their voices as partners in the assessment process can improve their confidence and therefore their learning. The objective of this action research was to support the introduction of the Essay Feedback Checklist (EFC) to first year management students at a British University. This research examined the use of EFC as an interactive two-way communication tool between tutors and students. The research also aimed to help management students to be more aware of the assessment criteria thus to be more engaged in feedback. Data was collected from students and tutors before and after the use of the EFC in order to highlight their perspectives regarding the effective use of the tool. The research's findings argued that students found the EFC useful to support engagement with the feedback and in improving their confidence through receiving quality feedback to develop their work further. Tutors and students claimed that the EFC created an interactive environment in providing feedback and it helped to open a dialogue about it, but they also highlighted some drawbacks.

Keywords: Feedback; Essay Feedback Checklist; Students' engagement; Confidence; Dialogue

\section{Introduction}

The literature on teaching and learning in higher education put a special focus on assessment and feedback as a core activity in the teaching and learning process. Most of the literature indicates the importance of assessment for learning (for example, Sadler, 1989, Biggs, 2003, Race, 2005, Norton, 200, Price et al, 2010). One of the main factors for successful learning is providing feedback that enabled learners to make sense of their learning (Race, 2010). Therefore, there is a formative feedback 
that focuses on how students' learning is progressing and a summative feedback that generates marks and levels and evaluate whether students can pass these levels or not (Price et al, 2010).

Assessment for learning involves: setting clear guidance for the standards or goals which should be achieved; providing information about how current achievement compares with standards; and giving feedback about how to take actions to reduce the gap between standards and actual work (Sadler, 1989). Therefore, effective feedback can be achieved when it is combined with effective instruction about the required performance and when students provided specific tasks or challenges to focus their attention and to increase their effort ( (Hattie and Timperley, 2007). Accordingly, the responsibility of teachers is to clarifying goals, enhancing commencement from students and encouraging self-assessment (Hattie and Timperley, 2007).

Thus, engaging students with feedback and giving them the information about their progress and motivating them to achieve the required standards, helped students to recognise their performance (Nicholls, 2004). Therefore, feedback can be seen as a system of guidance (rather than an event) which mainly based on continuous dialogue between students and tutors (Beaumont et al, 2011). This reflects that feedback has now become more student-centred (Bailey and Garner 2010) and for feedback to work in practice, it must connect with the students (Higgins et al, 2002:54).

This supports the argument that the teaching and learning activities, which are more active and with high student engagement, have a positive impact on the students' deep learning (Nicholls, 2002). This is simply because students' engagement helps them to ask if they have not received clear information or if they want more detail feedback about their work. The literature reveals, also, the importance of the students' selfassessment in developing their learning (Carles, 2006). Involving students to understand the feedback provided and to be a partner in this process help their learning (Fluckiger et al, 2010) and indicate a strong positive results and benefits to students (Black and Wiliam, 1998:15)

Therefore, good feedback practice should involve the development of reflection in learning (self-assessment) and helping tutors and students to clarify what is good performance by identifying the criteria or standards (Nicol and Macfarlane-Dick , 
2006). Achieving the previous objectives requires a way of communication between tutors and students which helps students to be aware of the assessment criteria and helps tutors to provide the expected feedback which students are looking for.

The literature indicated, also, that the information provided on students' progress though feedback has the capacity to turn each item of assessed work into an instrument for the further development of each student's learning (Hyland, 2000: 234). Although based on a reflective evaluation of the situation in higher education, feedback remains conceptualised and it is defined as transmission processes whereby tutors transmit feedback messages to students about what is right and what is wrong in their academic work. Therefore, they expect that students will use this information to improve their work further (Nicol and Macfarlane-Dick, 2006).

Thus, the question highlight here is: Are students aware of these standards? Do they know the main criteria for marking their work? There is also an issue related the quality of feedback which remains a major concern for higher education institution (Beaumont et al, 2011).

\section{Using the EFC (Thinking of Ways to Tackle the Problem)}

Norton (1990) asked students to rank in order the criteria which they thought their tutors were looking for and, then, she asked their actual tutors to look at the same criteria, identified by students, and rank them, also, in order of importance. Norton (1990) argued that there was a mismatch between students' and tutors' rankings whereby students put content fairly high in their rankings and tutors did not rank this criterion at all. The Essay Feedback Checklist (EFC) has been designed to list the assessment criteria used in essay marking and, then, ask students to rate how confident they felt when writing their essay by using a three-point rating scale for each assessment criteria (Completely Confident, Partially Confident and Not Confident At All) (Norton \& Norton ,2001; Norton et al, 2002). According to them, the idea of the EFC is that when tutors come to mark students' work, they look at students' own ratings and, then, put their own ratings underneath - whereby there is a big mismatch on where the tutor writes targeted feedback.

This study's rationale was to build a dialogue and an interactive approach in 
providing students with feedback. Highlighting the way in which tutors encourage students' engagement in assessment and feedback could have a positive effect on the level of knowledge as a shared process between tutor and students (Bloxham and Campbell, 2010:291). Bloxham and West's (2007) study identified that dialogue with tutors was a key aid in negotiating the meaning of both assessment guidance and written feedback. Higgins (2000:2) argued that students struggled to use tutor feedback effectively because they were unable to understand feedback comments and interpret them correctly. He argued that the reason was the failure of tutors and students to communicate. The use of the EFC, as a tool in giving feedback, could help to make assessments standards more transparent for students and it could create, also, a good opportunity to provide explicit assessment criteria and interactive feedback.

The rationale of using the EFC is to help students to be more engaged in assessment and feedback and to help them understand their tutors' expectations. The EFC works as a shared, interactive and two-way communication tool between tutor and students; this creates the circumstances for students to become gradually part of the assessment and feedback process. In the EFC's end section, and after asking students to rate their level of confidence in each assessment criteria, there is an additional section where students are asked, on submission of their assignments, to identify particular aspects of their work on which they would like feedback. This could help tutors to respond directly to students' enquiries about feedback and create an interactive dialogue between tutor and students.

The EFC could be used, also, as a tool that helps students to improve their essay writing (Norton et al, 2002). Designing the EFC involves making a list of the assessment criteria by which first year management students' essays are marked. Next, prior to submission of their assignment, students will be asked to rate these criteria. Then, their ratings are submitted along with their essays. In this case, the EFC will be a tool to help students judging their own work and

A reminder to students about the essential elements of their assignments that they should be focusing on while they are actually writing (Norton, 2009:163).

Also, the tutor can use the EFC to provide a rating of the assessment criteria. Then, this can be used to provide specific feedback about any differences between student's 
and tutor's ratings (Norton, 2009). In this case, the EFC is used to help the students to improve their essays and to help the tutor give effective feedback.

This research was designed to follow Norton and Norton's (2001) study with a particular focus on indicating first year management students' views of the usefulness of the EFC as a tool for helping them with the process of writing management essays and as a method of providing greater clarity within the tutor's written feedback. Furthermore, this research aimed to explore tutors' views of using tools such as the EFC.

\section{From Theory to Practice (The Context)}

From my practical experience of teaching first year students over five years at a British University, it was apparent that some first year management students found essay writing difficult and struggled to know exactly what writing a good essay required. They did not find their current feedback sufficiently helpful and, in some cases, they did not understand fully the essay assessment criteria. In turn, this might lead to some questions regarding tutors' feedback on essays; this was likely to be highlighted when second marking showed variation in tutors' feedback on some modules. Against this background, the research started to build on some discussions with peer tutors about the quality of tutors' feedback. This raised some potential questions about whether or not tutors gave what was understood to be 'effective feedback' in terms of giving more constructive and consistent comments to students. Furthermore, what was meant by the word 'effective' and it was questionable as to the extent to which there was a collective understanding of the term and how feedback could reflect on students' confidence. Hence, this research explored tutors' understanding of the effects of feedback on the students' learning.

The research sought to understand whether and, therefore, how the use of tutors' feedback on students' essays could be related to students' understanding and selfconfidence. It investigated any incremental improvements in essay writing which could be observed during students' first year of studying Management modules. Additionally, this paper investigated tutors' strategies to deal with essay feedback and sought students' views about the Essay Feedback Checklist (EFC) which could help them potentially to target those areas where they might help to improve their 
confidence level and therefore their essay writing.

In this British University, the teaching and learning strategy aims to 'establish assessment and feedback processes that enhance and deepen learning' (Teaching and learning strategic map in a British University). The strategy delivers the following strategic objectives to achieve this broad aim:

- To provide varied opportunities for the students to be assessed on their own work and work done with others.

- To ensure that the students understand fully the assessment criteria, processes and feedback channels which support their learning.

- To embed innovative practices for enhanced feedback mechanisms and approaches.

- To further develop and embed discipline and task-specific assessment criteria within an overarching institutional framework.

- To develop threshold standards for assessment and feedback (The strategic map, British University, 2012).

Within the Management School, the current practice was that feedback on essay scripts comes in two forms. Firstly, the marker highlights mistakes and writes relevant comments on the essay script. Secondly, a pro forma marking sheet is completed where the marker should highlight the positive aspects of the essay along with an outline of the key areas that the student needs to improve. The marking procedure requires that a sample of all scripts is second marked by another tutor who is familiar with the course content. The second marker provides feedback in the same way as the first marker. In the event of large discrepancies between the two markers, both markers would discuss their reasoning and come to an overall agreement upon the mark. Examples of essay marking criteria include: the extent to which the student provides a critical evaluation of the essay question which is backed up with relevant and appropriate academic literature; the overall essay structure (does the essay flow and include suitable introduction, body and conclusion); the proper English grammar; and appropriate academic writing.

Some students find feedback difficult to read and difficult to interpret. From the staff point of view, in some cases, the students do not pay attention to feedback and they look only for the mark or the grade. Over the last few years, many academic staff 
made the argument that, 'students care only about the grade and they do not care about feedback'. This leads to a question: Do tutors create the situation and environment to help students understand our feedback and work with assessment as a way to improve their learning?

This paper argues that there is a lack of communication between tutors and students in providing feedback and this may be the reason why students do not use feedback in a proper way. Accordingly, the research decided to use the EFC as a tool which could be used with essay writing to remind students of the marking criteria and to help them to self-assess their work and to allow tutors to give feedback on each criterion. With the EFC, the students can follow up feedback, also, with an open dialogue with tutors about their received feedback.

The focus for this action research was to support and improve first year management students' self- confidence through engaging them with the feedback on their essays. The generation of this research idea was based on a concern with first year Management students not understanding the assessment criteria for their essays and therefore they are not confident with the level of their work. Another issue was that, when they received their feedback, students frequently asked questions about its implications, for example, what does critical evaluation mean? How can I do more on referencing? How could I write my essay better next time? I am not confident with my work, what can I do?

\section{Research Questions}

Based on the previous review of the literature and on the review of the current situation at the Management School at a British University, this research's main objective was to help students to understand the assessment criteria and to help them receive and utilise effective feedback on their essays. It was believed that this might be achieved through giving suggestions and actions for students on how to reduce the gap between standards and actual performance and to motivate them to do better in their next essay. Therefore, the research questions were sought to provide in-depth insights and explanations to the following question:

To what extent will introducing an Essay Feedback Checklist (EFC) in the 
Management School's assessment process:

- Improve first year students' understanding of assessment criteria?

- Assist Tutors to target their feedback more effectively?

\section{Why Action Research?}

The main objective of using action research in this study was to help tutors to improve their teaching practices. There is a commitment to the idea that people can, and should, have a go at thinking about their practices and try to contribute to 'change' in their organizations. Here a question arises about 'How do I improve my practice? (Whitehead, 1989)

McNiff (2002) defined action research as:

Action research is a term which refers to a practical way of looking at your own work to check that it is as you would like it to be. Because action research is done by you, the practitioner, it is often referred to as practitioner based research; and because it involves you thinking about and reflecting on your work, it can also be called a form of self-reflective practice (McNiff, 2002)

Accordingly, action research could be a way to help practitioners to improve their own practices. Although the definition reflects the individual and the subjective view in doing action research, it is aligned with this paper's objective in doing action research in teaching practices. However, this is not the only objective of doing this research. There is, also, a concern about the need to investigate the current situation regarding feedback at the Management School and, probably, to take the initiative to open a dialogue about assessment and feedback in the University. Therefore, this may strongly support, also, Norton's following definition of action research as a pedagogical work:

The fundamental purpose of pedagogical action research is to systematically investigate one's own teaching/learning facilitation practice with the dual aim of modifying practice and contributing to theoretical knowledge...Using a reflective lens to look at some 'problem' or initiative and then determining a methodical set of steps to research that problem/initiative and to take action (Norton, 2009, xv-Xvi)

In conclusion, this action research's objective was to put down a marker on the Management School at a British University current teaching and learning activities by 
exploring students' and tutors' points of view about the feedback provided on essays. Also the aim was to reflect and improve teaching practices by using a new tool of giving feedback to students, namely the EFC.

\section{Research Design and Method}

This research used a multi-methodological approach. Although a first draft of the EFC was developed, the study was very keen to engage the Management School tutors in developing the checklist. Once we had agreed on the checklist, students were asked to complete it when writing their essays. The next stage of data collection was a questionnaire to those students who participated in the study. The questionnaire collected students' views on whether or not they considered that the EFC was useful; the ease/difficulty of completing the EFC; whether or not they considered that the feedback provided by the EFC gave them a better understanding of how to improve their work; and whether or not they considered that the EFC ought be adopted at the Management School (and at what level - e.g. all years or only 1st year). A focus group was arranged with some students to obtain more in depth insights about their experience in using the EFC.

\section{Ethical Issues and Limitations of using EFC}

In order to protect students and staff, data was collected from participants in a very careful way. The research took steps to ensure that participation in the project was voluntary and there was not any abuse of power from tutors to force students to become involved. The research has been approved by the local ethical committee to start collecting data from tutors and students. Students were provided with the information about the possible benefits of taking part in this research to improve their essay writing and to help them to obtain effective feedback which helps them in the future to enhance their essay writing. Students and tutors were told that all their responses were anonymous; also, if they preferred their quotes not to be used, they could say so in the consent form.

There was a mixed reaction from the tutors to the trialling the EFC. Some positive reactions were received to the ideas and a number of tutors were happy to become involved in the research. Others were less forthcoming with comments and might be 
unwilling to participate. The research respected any colleague's right not to participate in the study. The research was trying to be aware of the main limitations of using the EFC as outlined in Norton (2009). The EFC's first limitation was that students might not give an honest rating to their work since they might consider that it would affect the tutor's marking. In order to alleviate this issue, students were provided with information that the essays will be marked in the traditional way before being reassessed using the EFC. This ensured, also, that marking remained consistent between the assignments marked under this research and with those not involved in the research. Another concern about the EFC related to tutors and how they might not wish to give feedback in this way but prefer to write on the essay itself. I was very keen to create a dialogue about the research idea and how it could help both students and tutors. The research worked to build up a collaborative discussion regarding the idea. The tutors were asked to help to adapt and to refine the EFC. Two tutors agreed to take part in this research; this represented a good sign of their interest in the research idea.

\section{Research Findings}

The research findings are reported in the following stages.

\section{Stage One: Design the EFC with the Tutors}

In order to investigate the tutors' perspectives regarding feedback, this action research started by interviewing peers about their perspectives regarding the quality of essay feedback.

The following quotes present some of their responses when I began to explore the research idea with them and to ask them about the EFC as a tool in providing feedback. One tutor indicated that:

It is a good idea to think about the level of confidence for first year students. Actually we deal with them as adults but they haven't enough experience to cope with the university work. We always aim to institutionalise them through putting frameworks and forms that might help them to improve their learning and it could help us as well. They should be aware of the new rules of the game! (TA) 
The above quote argued that using feedback forms or frameworks might work in controlling students to be completely under the university umbrella. The quote reflects, also, the importance of considering the first year management students' level of confidence and how to develop it. The quote reflects, also, the rational of assessment in higher education from a tutor's point of view which is to set the rules that students should follow. The following is another quote supported the same idea that feedback was a controlling tool used by tutors to enforce students to cope with the university regulations and procedures:

Assessment is problematic. It controls students. I wish there was no assessment. What we do is a memory learning not assessment. The market should assess students not us. It is the job of the employer. Can you ask your students if we remove assessment from the course, what do they think? (TB)

The above quotes confirmed still the previous idea that some tutors recognised assessment as a tool to control students and to keep their work within the expected levels. One tutor reflected their conservative view regarding the research idea as follows:

Well, we should be careful. Are we going to be giving them feedback or giving them a chance to question our academic judgement? I think some students want us to mother them not to give them a feedback (TC)

The previous quote reflects the reaction of some tutors when I explained my project idea to them. They refused the idea of sharing feedback criteria with students. They argued that this might open the door to students' questioning their academic judgement. When I started to argue that it was students' right to follow up our feedback, they claimed that this would reflect negatively on our role as academics and on our academic freedom.

During the interviews, there were some discussions regarding our performance in management classes and how this could reflect on the students' level of learning. The following quote reflects this:

It is good to ask students to be more critical in their writing or to write a comment like it is a descriptive writing, but the question is, are we provide students critical lecture or materials to help them build up these skills? (TD) 
Some tutors suggested some actions to develop their practices. The following quotes represent two of the tutors' action plan to provide the students with some study skills sessions to help them to understand and be aware of the marking criteria which we used in marking essays. The objective of these sessions is to help students to be familiar with the standards which tutors were looking for. There was, also, a suggestion to apply the research idea with students in different years.

I'm going to prepare a study skills lecture for first year students next year which involves a session about essay writing, referencing and plagiarism. I wish this could help them in writing their essay (TE)

It may be helpful as well to apply the same idea for third year students because they need more help in writing their essays and giving them feedback. The same idea could be applicable for the international partner (TF)

It was clear from the above mentioned quotes that tutors had different themes and ideas. Some of academics recognised students' engagement in feedback as a negative sign of their academic work. Some others argued that assessment and feedback was for the purpose of controlling students within the institutional regulations. Some tutors engaged positively with the research idea and started to think about how to develop their teaching practices. Tutors agreed that the criteria involved in the EFC were to evaluate whether students:

- Addressed the question throughout the essay in a correct way;

- Organised the essay clearly with structure appropriate to the question;

- Put forward a relevant argument of good quality;

- Synthesised a range of material into a coherent whole;

- Demonstrated a depth of understanding relating to underlying management issues;

- Evaluated theoretical concepts and research evidence;

- Referenced according to management requirements;

- Checked for spelling and grammar; and

- Wrote in an appropriate academic style. 


\section{Stage Two: Before Using the EFC: Students' Expectations}

120 first year management students out of 300 students were told to write down on a piece of paper their thoughts about the importance of feedback and what they expected from feedback on their essay. The following voices represent examples of students' thoughts about the importance of feedback:

Feedback is important because it can improve my essay in the future and know the mistakes I have done. This will help me not only in one module but in other modules as well

Essay feedback is important to me as it allows me to understand the strong and weak points of my writing. This will give me the chance to apply these recommendations to future essays and to improve my writing and my analysis

It is important so that we can learn from it. We will know what we get wrong and what we have got right

My feedback is important because I want to know if it was worth the effort or not

We can learn from feedback what we are doing wrong, what get right and how to improve my essay

From the previous quotes, it was clear that students were looking for constructive feedback because they wanted to learn how to improve their performance next time and to know the positive and negative points of their essay. Some students claimed that they were looking for a detailed feedback in criteria like grammar or referencing. They highlighted, also, the importance of providing feedback on specific criteria. In addition, students were asked about their expectations for essay feedback. The following represent some examples of students' expectations for:

\section{Timely Feedback}

I think the best feedback should be timely and helpful

I want to know overall points, good and bad points and future recommendations.

I want feedback before the end of the term to be able to discuss it with my tutor I need to know my mark, strengths, weaknesses and where I need to improve my writing. 
I would like to see my feedback soon after the submission of my essay

\section{Specific Feedback}

I am looking for individual areas of improvement need to be highlighted

My essay is a problem, I want a specific guidelines and feedback not a general ones

\section{Constructive Feedback}

I expect feedback allows us to transition from A level techniques to a degree level as it tells me how to improve my work and get higher marks

I expect feedback to tell me what I did well and what I need to improve in the future and how?

\section{Motivational Feedback}

Feedback enables me to get know my mistakes and correct them. I expect as well it motivates me on writing better essays

I want feedback that encourages me to work harder and reduce further mistakes

I expect feedback to giving us constructive, clear criticisms and motivate me doing better next time

\section{Detailed Feedback}

I want to know in detail what are strengths and weaknesses in my essay. Whether is good or not, how can I improve my essay next time. Also, the references are correct or not

I want feedback to show me in detail what we can develop on and take on board

\section{Personal Feedback}

Most feedback are generic, I expect the tutor to guide me on what to include or exclude in my essay so as to strengthen my essays and this could help me know how to write good ones

I am looking for tutors' feedback and their opinions, comments on my writing style and layout

It was clear from the previous comments that first year management students were active learners because they were looking to develop their writing skills. They were interested in receiving feedback on their essays that could help them to learn and to improve their writing skills in the future. Also, they were looking for feedback which 
was constructive, motivational and specific to further developing their work. Students also highlighted the importance of feedback to support their learning transition from school to university. The above quotes noted the importance of the positive and motivational feedback and the beneficial effect on students learning.

\section{Stage Three: After the EFC: Experience of Feedback}

The main objective of this stage in the study was to explore to what extent there could be a mismatch between students' and tutors' ratings on the assessment criteria. This could be achieved through providing a descriptive analysis of the findings. For the students' rating and the tutors' rating, a score of 3 was given to 'Completely Confident' (C), 2 for 'Partially Confident' (P) and 1 for 'Not Confident at All' (N). 40 students have been accepted to use the EFC and submit the form with their essays.

The findings indicate clearly that there is a mismatch between students' evaluation to their work and tutors evaluation. For example where students were confident about their work in referencing as marking criteria, there is a large difference between tutors evaluation to this criteria. This finding was slightly surprising as I had expected students to do better with referencing since we had given them a session about how to write referencing and how to avoid plagiarism.

In the area of 'Understanding', where students were expected to understand the essay question and the material provided to support their writing and evaluation, students rated themselves as 'Completely Confident.' On the other hand, tutors evaluated 'Understanding' as a criteria that students not confident with because their work shows less understanding to the marking criteria. This finding supported the argument that it was difficult for first year students to shown depth of understanding to some management issues because most of their work was descriptive without deep analysis of the topic. It was clear from the findings that students evaluated themselves higher than tutor evaluation. This reflected that students might need more clarification of the standards required in these criteria and that they might need more help from tutors to explain the difference between their actual performance and the expected performance.

\section{Stage Four: Questionnaire}


In order to obtain more information from students about their experiences in using the EFC, students were asked to complete 'The Assessment Experience Questionnaire' which adapted from Gibbs and Simpson (2003). The objective was to obtain some insights from students regarding their experiences with the EFC. 30 students (out of 40) agreed to complete. They have been asked to return the questionnaire back after receiving their feedback from tutors.

Looking at the overall figures in Table (1) it can be seen that $76.7 \%$ of students thought the EFC helped them with clear instructions about the criteria used in marking their essays.

\section{INSERT HERE Table (1)}

\section{Table 1: Students' Responses to the Questionnaire}

Only $4 \%$ of students agreed that the EFC could help them to compare their work with others. The highest percentage of students indicated that the EFC helped them to understand things better and to show how to do better next time (43.3\% and 86.7\%). $70 \%$ of the students claimed that they did not understand some of the feedback. This reflects that, in some cases, there is a miscommunication in terms of the languages used in the feedback provided to the students.

This finding supported Higgins et al's (2001) view that there was a problem in communicating assessment feedback. They argued that shared understanding of the meanings and the languages, used in the feedback provided to students, could be helpful to improving their performance. The interesting figure from the questionnaire was that all students (100\%), who completed the questionnaire, agreed that the EFC helped them to confidently evaluate their work and they are very keen to read the feedback not just their marks. Overall, the findings supported the argument that students found the EFC helpful and they felt positive about using the EFC in obtaining feedback on their essays and they feel confident with using the tool.

\section{Stage Five: Focus group}


From a potential of 40 students, 8 students joined a focus group to obtain more indepth insights about their experiences with the EFC. The following quotes came from students' focus group discussions about the EFC's usefulness:

The EFC had made me feel confident and realise how important proof reading is and made sure I had completed grammar and spell check manually. This is a vital skill which is also going to help throughout life as well as for all my other module assignments. EFC also can be seen as a revision tool as it made me go back to notes numerous times to see if there was another way of looking at the argument (Student A).

The previous quote pointed out that students realised the importance of being familiar with the criteria used in marking essays and how this reflected on him/her confidence level. The comment showed, also, that students used the EFC as a revision tool to improve writing their essays.

One of the comments was from a student who did not find the EFC useful; he claimed that the reason was the lack of information about the gap between the actual work and the standards. This student wanted still to know more about the marking criteria:

It isn't helpful at all. I'm still wondering how critical arguments look like...I honestly thought I did it in the essay, so sad! (Student B)

One student gave the following comment about their experience of using the EFC:

I like the way the EFC is based on constructive feedback. I think most students would be devastated if they are already feeling down from the marks received and then receive only negative feedback expounding on their weaknesses. Instead the EFC is well balanced in giving feedback on strengths and weaknesses. It allows an avenue for students to have a better insight into their essays especially when students don't have a chance to see their tutors after getting them back. It is impossible for tutors to remember every single script they graded so it is good to complete an EFC as and when they are through with it while the memory is fresh. It definitely prevents a mob of students from mobbing the tutors for explanations and more marks (Student C).

It was clear from the previous comment that students recognised the EFC as a tool for giving positive comments on essays as well as negative ones. Student highlighted, also, that the EFC could save time for students and tutors in meeting up for more clarification of the feedback. 
As indicated in the literature review, feedback could be a tool to encourage students to develop their writing and to feel confident in self-evaluating their work. The following comment supports this view.

I found the EFC feedback very useful in understanding what I did well and where improvements could have been made, it was very useful feedback to take into my next essay where the feedback given can be applied and weak areas focused on. It gives clear descriptions of exactly what was done well, and an indication as to my personal strengths, and how I need to develop throughout my university course. It really helped me to be more confident in my writing. I liked the well done comment at the end of the EFC which encouraging and motivating me to do better next time (Student E).

One of the objectives of using the EFC in this study was to help students to be aware of the marking criteria of their essays. The following comments from students support this objective:

EFC gave an idea to the marking criteria and as to what was is expected. Also useful as an aid to writing the essay as a checklist. After feedback is useful as a reflective tool to help improve future assignments (Student F).

Before submitting my essay, EFC gave me a clear idea of exactly what the marker would be looking for in my essay which helped me to write and structure my essay confidently. After - it indicated how successful I was in each criteria which helped me understand the overall mark I received and it has told me how to improve next time (Student G).

After receiving my assignment, EFC gave me feedback on the mistakes that I had made and what I could improve on. Precisely on the organization of the essay and the relevance of the argument which was mostly touched upon, from this I know that I could present as much data and resources. However, they need further explanations and evaluations that still link back to the question and maintain a relevant argument in the essay (Student $\mathrm{H}$ ).

It was clear that students used the EFC before writing their essays and, then, after receiving their marks. Before writing the essay, the EFC was used to check the marking criteria in order to be familiar and confident with the standards and it was used, also, after receiving the feedback. The previous comments indicated the importance of using the EFC as a tool which could encourage students not to look only for their marks but also to follow up their feedback. The EFC could be used, also, as an aid to help students think about some actions to improve their essay 
writing. The conclusion from students' previous comments is that most of the first year management students found the EFC to be a useful tool in their essay writing. Students stated that, before writing the essay, the EFC could be used to remind them of the marking criteria. After receiving the feedback, it could be used, also, to show them how to do better next time with their writing. They also argued that the EFC helped to self-evaluate their work that reflected positively on their confidence level.

\section{Discussion}

The objective of this action research was to explore the perspectives of students and tutors for the use of the Essay Feedback Checklist (EFC). It also aimed to help first year management students to be more familiar and aware of the assessment criteria of their essay before starting write it up. The results of this study indicate that students found the EFC to be a positively supportive tool in essay writing. They pointed out the importance of having feedback for each marking criteria in to know clearly their writing limitations and how to improve it further.

The findings from the questionnaire and from the focus group supported the view that most students were very interested in building up two-way communication and in developing a dialogue with their tutors regarding feedback. Students found the EFC makes significant help in reminding them of the marking criteria before submitting their essays. Also, after receiving their feedback, they used it to consider the tutors' comments about their work. So, the EFC encourage students to actively question their understanding of their own work in relation to the assessment criteria (Wakefield et al, 2014: 260).

In the focus group, students indicated that they were waiting to know how the tutors evaluated their work in order to compare it with their own evaluation. Students believed, also, that they needed to add their voices to the feedback provided from their tutors. This is related to the idea that feedback should be empower students and encourage them to be an active learner and to develop their employability skills through judging their work (Sadler, 2010). 
In addition, following interviews with tutors regarding the findings of the study showed that most tutors held a conservative view regarding the use of the EFC as a tool to provide feedback. They outlined many reasons for this view. For example, they claimed that the EFC was a time consuming tool and they argued, also, that students did not care about feedback and they did not use it to improve their writing. The following quotes provide some of these voices:

The research findings are interesting but the form is simply representing more work load for academics. I do not want to do any extra work in feedback. I am marking more than 200 scripts!

I have done mid-term exams, just two students out of 18 came to see me to ask about my feedback for their marks. I asked them many times to come and see me; none of them used my office hours. Maybe everything is clear for them! I want to say that student's do not using our feedback

This view was totally opposite to students' points of view. Students who shared in this study showed interest in receiving feedback from their tutors. They insisted that they were looking not only for the marks but, also, for the feedback and they were very interested in following up this feedback with actions to improve their writing. The differences in the two perspectives return to missing communication ad dialogue between tutors and students. Therefore, there is a need for a greater focus to help student make sense of feedback (Evans, 2013). However, the relationship between feedback and achieving certain goals is complex and a problem occurs when feedback is not lead to achieving these goal (Hattie and Timperley, 2007).

The findings of this study support the argument that the EFC as interactive tool helps students to understand the assessment criteria and be more involved in the assessment process. This also related to the idea that when students share a commitment to engage with feedback and to seek and receive it, this leads to achieving effective performance and goals (Hattie and Timperley, 2007).

The study also supports the argument that the use of the EFC produces significantly higher performance from students because students have a chance to self-assess their work before submission (Wakefield et al, 2014). This finding supports the argument that assessment and feedback can motivate and challenge the learner to develop their skills (Nicole and Dick, 2006). 


\section{Conclusion}

This study investigated the use of the EFC as two way communication tool to engage first year students with assignment feedback. In this action research, tutors and students participated in the research. In addition, students' commented-on the EFC were collected and analysed in order to gain a better understanding of the findings.

The study confirmed that using a tool to engage students when they writing their assignment helped them to read the provided feedback and to build up a dialogue about it with the tutors. This also encourages students to take some specific actions on how to improve their writing (for example, how to evaluate different arguments). The findings of this study support the argument that students prefer an interactive tool to understand the marking criteria and be more involved in the assessment process.

The findings of this study support further research in different areas such as the effective use of self-assessment and peer assessment; and the use of on technology based tools on engaging students with feedback. The findings indicate, also, that future researches may impact on enhancing first year management students' learning and their level of confidence in higher education. It could be argued considerable emphasis and research should be placed on students as partners and active agents in the feedback process.

In sum, the use of the EFC as an initiative in this university helped tutors to revise their teaching practices accordingly by encouraging students to evaluate their performance based on the marking criteria. It also supported an introduction of study skills sections for first year students to support their understanding to the marketing criteria to their management assignment.

Acknowledgement: This work was supported by the Higher Education Academy under Grant [GEN525], Transforming Assessment in Higher Education Pilot Scheme.

\section{References}

Bailey, R., and M. Garner. 2010. "Is the Feedback in Higher Education Assessment 
Worth the Paper It is Written on?" Teachers' Reflections on Their Practices, Teaching in Higher Education 15 (2): 187-198.

Beaumont, C.; O’Doherty, D. M.; Shannon, L. (2011). 'Reconceptualising assessment feedback: a key to improving student learning? Studies in Higher Education, 36, 6, 671-687

Black, P.J. \& Wiliam, D. (1998). Assessment and Classroom Learning. Assessment in Education, March,7-74. http://dx.doi.org/10.1080/0969595980050102

Biggs, J. (1999). Teaching for Quality Learning at University. Buckingham: SRHE and Open University Press.

Biggs, J. (2003). Teaching for Quality Learning at University, 2nd Edition, Buckingham: Society for Research into Higher Education and Open University Press.

Bloxham, S. \& West, A. (2007). Learning to write in higher education: Students' perceptions of an intervention in developing understanding of assessment criteria. Teaching in Higher Education, 12, 1, 77-89.

http://dx.doi.org/10.1080/13562510601102180

Bloxham, S \& Campbell, E. (2010). Generating dialogue in assessment feedback: exploring the use of Interactive cover sheets. Assessment and Evaluation in Higher Education, 35:3,291-300. http://dx.doi.org/10.1080/02602931003650045

Evans, C. (2013). Making sense of Assessment Feedback in Higher Education. Review of Educational Research, 83:1, 70-120.

Fluckiger, J., Vigil, Y., Tixier, Y., Pasco, R., \& Danielson, K. (2010). Formative feedback: Involving students as partners in assessment to enhance learning. College Teaching, 58, 136-140. doi:10.1080/87567555.2010.484031

Gibbs, G \& Simpson, C. (2004). Conditions under which assessment supports students' learning. Learning and Teaching in Higher Education, 1, 3-31.

Gibbs, G. \& Simpson, C. (2003). Measuring the response of students to assessment: the Assessment Experience Questionnaire. 11th International Improving Student Learning Symposium, Hinckley.

Hattie, J. \& Timperley, H. (2007). The Power of Feedback. Review of Educational Research, 77:1, 81-112.

Higgins, R., Hartley, P. \& Skelton, A. (2001). Getting the message across: the problem of communicating assessment feedback. Teaching in Higher Education. 6: 2, 269-274. http://dx.doi.org/10.1080/13562510120045230 
Higgins, R., Hartley, P. \& Skelton, A. (2002). The conscientious consumer: reconsidering the role of assessment feedback in student learning. Studies in Higher Education.27, 1, 53-64. http://dx.doi.org/10.1080/03075070120099368

Hyland, P. (2000). Learning from feedback on assessment. In P. Hyland, The Practice of University History Teaching. Manchester: Manchester University Press.

McNiff, J. (2002). Action research for professional development. Retrieved January 15, 2013 from http://www.jeanmcniff.com/booklet1.html.

Morris, E.; Orr, S.; Payne, E.; Price, M.; Rust, C.; Smith, B. \& Waterfield; J.; (2012). The Marked Improvement, Transforming Assessment in Higher Education. The Higher Education Academy. Retrieved January 13, 2014 from http://www.heacademy.ac.uk/resources/detail/assessment/a-marked-improvement.

Nicol, D. \& Macfarlane-Dick, D. (2006). Formative assessment and self-regulated learning: A model and seven principles of good feedback practice. Studies in Higher Education.31, 2,199-218. http://dx.doi.org/10.1080/03075070600572090

Nicholls, G. (2002). Developing Teaching and Learning in Higher Education. Routledge Falmer.

Nicholls, G.M. (2004). The scholarship of teaching as a core professional value: what does this mean to the academic? Teaching in Higher Education. 4, 1, 29-42. http://dx.doi.org/10.1080/1356251032000155812

Norton, L.S. (1990). Essay-writing: what really counts? Higher Education. 20, 411442. http://dx.doi.org/10.1007/BF00136221

Norton, L.S. \& Norton, J.C.W. (2001). The essay feedback checklist: How can it help students improve their academic writing? Paper and workshop given at the first international conference of the European Association for the Teaching of Academic Writing across Europe (EATAW), Groningen, The Netherlands, 18-20 June.

Norton, L., Clifford, R., Hopkins, L., Toner, I.,. \& Norton. J.C.W. (2002) Helping psychology students write better essays. Psychology Learning and Teaching, 2, 2, $116-126$

Norton, L.S. (2009). Action Research in Teaching and Learning: A Practical Guide to Conducting Pedagogical Research in Universities, Abingdon: Routledge.

Price, M.; Handley, K.; Millar, J. \&O’Donovan (2010). Feedback: all the effort, but what is the effect? Assessment \& Evaluation in Higher Education. 35:3, 277-289.

Price, M.; Carroll, J.; O’Donovan, B.; \& Rust, C. (2011), If I was going there I 
wouldn't start from here: a critical commentary on current assessment practice. Assessment \& Evaluation in Higher Education. 36:4, 479-492.

Race, P. (2010). Making learning happen: a guide for post-compulsory education. 2nd Edition, SAGE Publications. London.

Sadler, D. R. (1998). Formative assessment: Revisiting the territory. Assessment in Education: Principles, Policy \& Practice. 5, 77-84.

http://dx.doi.org/10.1080/0969595980050104

Teaching and Learning Strategic Map for English University, 2010-2015 Retrieved December 13, 2013.

Wakefield, C.; Adie, J.; Pitt, E. \& Tessa, O. (2014). Feeding forward from summative assessment: the Essay Feedback Checklist as a learning tool. Assessment \&Evaluation in Higher Education, 39:2, 253-262.

Whitehead, J. (1989). Creating a living educational theory from questions of the kind, 'How do I improve my practice? Cambridge Journal of Education, 19, 1, 137153. http://dx.doi.org/10.1080/0305764890190106 
